\title{
Clinical performance of endoprosthetic and total hip replacement systems
}

\author{
P. M. SANDBORN, B.S.; S. D. COOK, Ph.D.*; A. F. HARDING, B.S.; M.A. KESTER, Ph.D.; \\ R. J. HADDAD, JR., M.D. \\ Rehabilitation Research and Development, Veterans Administration Medical Center, \\ New Orleans, Louisiana 70146 and Department of Orthopaedic Surgery, Tulane University School of Medicine, \\ New Orleans, Louisiana 70112
}

\begin{abstract}
A retrospective study of endoprosthetic replacements and total hip prostheses was undertaken to determine factors that have the greatest effect on the success or failure of femoral hip components. A total of 227 endoprostheses were inserted within the years 1970 1985. Of these, 67 components ( 29.5 percent) required removal for various reasons. For an endoprosthesis, the most significant factor in determining the chances of success appeared to be the initial insertion diagnosis. Patients who received an endoprosthesis for an ailment which affected only the femoral side of the joint (such as traumatic fracture) had a much lower rate of failure than those patients with disease etiologies that could affect the acetabulum (such as osteoarthritis). The opposite was found for total hip prostheses. Of the 641 total hip devices inserted, 148 (23.0 percent) required removal. The highest rate of failure among these total hip components was for those devices inserted for trauma and the lowest rate of failure was for those inserted for osteoarthritis. Age at the time of insertion also proved to be of importance when estimating a hip component's chance of survival. For both endoprosthetic replacements and total hip arthroplasties, patients younger than 50 years of age at insertion experienced a failure rate almost twice that of those patients more than 50 years of age at insertion.

DOI $10.1682 / J R R D .1987 .07 .0049$
\end{abstract}

\section{INTRODUCTION}

Prosthetic replacement of the hip is a common surgical procedure for the treatment of joint degen-

\footnotetext{
*Address correspondence to: Stephen D. Cook, Ph.D.; Department of Orthopaedic Surgery, Tulane University Medical School, 1430 Tulane Avenue, New Orleans, Louisiana 70112. Phone (504)588-2273
}

eration and femoral neck trauma. Although the procedure has proved successful in relieving pain and restoring function in a large percentage of cases, it is not without complications. Long-term followup studies have documented success rates of approximately 70 to 95 percent at an average of 5 years postoperative $(2,13)$ with followup studies at 10 years indicating continued success at this level (15).

Studies have compared success and failure rates for various implant designs such as the Charnley (2) and Charnley-Muller (3) total hip prostheses. These studies revealed loosening to be the leading complication causing pain and discomfort among patients. Ritter (13), in a 7-year followup study, found that patients receiving Muller total hip prostheses experienced a higher percentage of complications than did patients with Charnley designed devices. A comparison of Austin Moore and Fred Thompson endoprostheses (8) showed few complications within either group as long as a component of the proper size was used. No difference in performance between the two designs was noted.

A study of a series of total hip components removed for aseptic loosening (9) found that femoral components of the Charnley-Muller design, if inserted in an active, heavier patient who had had prior femoral head replacement, were at risk of component failure. A comparison of total hip replacement patients with initial diagnoses of either osteonecrosis or osteoarthritis revealed little difference in success and failure rates between these diagnoses at insertion (12). 
Journal of Rehabilitation Research and Development Vol. 24 No. 3 Summer 1987

Andrews (1) reported the rate of infection among rheumatoid arthritis patients to be greater than for any other insertion diagnosis group in a study of total hip arthroplasties experiencing deep infection postoperatively. Wilcock (16) studied insertion age as a factor in hip implant failure and found patients younger than 70 years at the time of insertion to be at greater risk of failure than those patients older than 70 .

Researchers have also investigated other factors which may affect the success of an arthroplasty, such as complications related to the technical aspects of arthroplasty (4) and initial patient selection (7). Obtaining proper positioning of each implant at the time of surgery was found by Coventry (4) to be an important factor in eliminating component failure. Excessive anteversion or retroversion of either component, causing impingement of the neck of the femoral component against the acetabular component, often leads to joint dislocation (7).

When choosing a treatment modality, a surgeon must consider all factors that could influence the clinical results, in order to determine the best procedure for the individual patient. The majority of studies, such as those mentioned above, review only patients who fit a particular criterion. Therefore, a study of a general population of all artificial hip recipients may reveal information not obtainable in the smaller, limited studies. Such a study of a large number of retrieved total hip components and endoprostheses has not been reported in the literature. The purpose of this study was to review retrospectively both primary and revision endoprosthetic and total hip arthroplasties at Tulane University affiliated hospitals, in order to discern factors affecting their success or failure. All patients except those receiving porous-coated devices were included for the 15-year evaluation period.

\section{MATERIALS AND METHODS}

During the years 1970-1985, the insertion and removal histories of patients with total hip prostheses and endoprosthetic replacements were collected as part of an implant retrieval and analysis program sponsored by the Veterans Administration. The protocol, in compliance with ASTM specification F561-78, included a review of the patient's clinical history including age at implant insertion, sex, weight, initial diagnosis, reason for implant removal, and implant time in situ. Direct patient contact was not feasible as a data collection method, thus the activity level and the mortality of the total patient population is unknown. Clinical records of failed devices were documented at implant insertion and removal. Each implanted device was recorded separately, therefore all counts and percentages refer to individual prostheses and not individual patients.

\section{Endoprosthetic Devices}

A total of 227 non-porous-coated endoprosthetic devices were inserted in 127 males and 100 females. The prostheses inserted included the Fred Thompson design (78 cases, 34.4 percent), the AustinMoore design (67 cases, 29.5 percent) and the Leinbach design (13 cases, 5.7 percent). Other miscellaneous designs constituted 27 (11.9 percent) insertions, while 42 were of undocumented design.

The major insertion diagnosis for the endoprostheses was trauma (153 cases, 67.4 percent). This was followed by the revision of 19 cases $(8.4$ percent) of previously failed hardware including 10 endoprostheses, 3 surface replacements, 2 Richards screws, 1 Jewett nail, and 3 unknown devices. Avascular necrosis (14 cases, 6.2 percent) and osteoarthritis ( 12 cases, 5.3 percent) were other insertion diagnoses. Nonunion and aseptic necrosis accounted for 7 ( 3.1 percent) and 5 ( 2.2 percent) cases, respectively. The remaining 17 endoprostheses were inserted due to other etiologies or for unknown causes.

Of the 227 endoprosthetic devices followed during the study, 67 (29.5 percent) required revision which included 6 second revisions. Reasons for implant removal included general pain without a recognizable cause ( 21 cases, 9.3 percent), followed by loosening or instability (18 cases, 7.9 percent) and infection (10 cases, 4.4 percent). Dislocation was the reason for the removal of seven devices (3.1 percent), while trauma was the reason for three ( 1.3 percent) device removals. Shortening and acetabular protrusio separately caused two devices to be removed ( 0.4 percent each). Six devices were removed for unknown reasons. Insertion and removal data for the endoprostheses studied is summarized in Table 1.

The survivorship table for endoprosthetic insertions, shown in Table 2, was constructed using the methods described by Hill (5). The probability of 
Table 1

Summary of insertion and removal data for endoprosthetic replacements

Insertions

\begin{tabular}{lcc}
\hline Diagnosis at Insertion & $\begin{array}{c}\text { No. Implants } \\
\text { Inserted }\end{array}$ & $\begin{array}{c}\text { \% of Total } \\
\text { Insertions }\end{array}$ \\
\hline Trauma & 153 & 67.4 \\
Revision of Previous & 19 & 8.4 \\
Hardware & & \\
$\quad$ Endoprostheses & $(10)$ & $(4.5)$ \\
Surface Replacements & $(3)$ & $(1.3)$ \\
Richards Screw & $(2)$ & $(0.9)$ \\
Jewett Nail & $(1)$ & $(0.4)$ \\
Unknown & $(3)$ & $(1.3)$ \\
Avascular Necrosis & 14 & 6.2 \\
Osteoarthritis & 12 & 5.3 \\
Nonunion & 7 & 3.1 \\
Aseptic Necrosis & 5 & 2.2 \\
Dislocation & 2 & 0.9 \\
Pain & 2 & 0.9 \\
Rheumatoid Arthritis & 1 & 0.4 \\
Tumor & 1 & 0.4 \\
Unknown & 11 & 4.8 \\
\hline
\end{tabular}

Removals

\begin{tabular}{lcc}
\hline Reason for Removal & $\begin{array}{c}\text { No. Failed } \\
\text { Implants }\end{array}$ & $\begin{array}{c}\text { \% of Total } \\
\text { Insertions }\end{array}$ \\
\hline Pain & 21 & 9.3 \\
Loosening/Instability & 18 & 7.9 \\
Infection & 10 & 4.4 \\
Dislocation & 7 & 3.1 \\
Trauma & 3 & 1.3 \\
Shortening & 1 & 0.4 \\
Acetabular Protrusio & 1 & 0.4 \\
Unknown & 6 & 2.7 \\
\hline
\end{tabular}

failure within a year was calculated based on the number of implants remaining in situ at the beginning of the year. The expectation of life is the average number of years an implant can be expected to remain in situ based on the number of implants surviving at the beginning of the year.

\section{Total Hip Arthroplasties}

The records of 641 non-porous-coated total hip insertions were also reviewed. All prostheses studied consisted of a metal stem and a plastic acetabular component. The prostheses included 416 implants inserted in males and 225 implants inserted in females. The Charnley-Muller design was the most commonly documented prosthesis inserted (87 cases, 13.6 percent). This was followed by 55 prostheses of the Moore I-Beam design (8.6 percent) and 42 prostheses of the Charnley design (6.6 percent). The Muller type total hip prosthesis accounted for 21 (3.3 percent) cases, the dual or taper lock design accounted for 19 (3.0 percent) cases and the AufrancTurner design for 14 ( 2.2 percent $)$ cases. The remaining insertions included various other prosthetic designs or were of undocumented design.

The insertion diagnoses for the 641 total hip prostheses were osteoarthritis (219 cases, 34.2 percent) followed by revision of previous hardware 158 cases (24.6 percent) including 43 total hips (both components), 31 total hips (femoral components only), 33 endoprostheses, 14 surface replacements, 4 bipolar endoprostheses, and 33 other or unknown devices. Other insertion diagnoses included aseptic necrosis ( 66 cases, 10.3 percent), avascular necrosis

Table 2

Survivorship table for endoprosthetic insertions.

\begin{tabular}{|c|c|c|c|c|c|c|}
\hline $\begin{array}{l}\text { Years Post- } \\
\text { Operative }\end{array}$ & $\begin{array}{l}\text { No. of hips } \\
\text { in situ* }\end{array}$ & $\begin{array}{l}\text { No. of } \\
\text { Failures }\end{array}$ & $\begin{array}{l}\text { Probability } \\
\text { of survival }\end{array}$ & $\begin{array}{c}\text { Probability } \\
\text { of failure }\end{array}$ & $\begin{array}{l}\text { Expectation } \\
\text { of life }\end{array}$ & $\begin{array}{c}\text { \% Failure } \\
\text { of Total }\end{array}$ \\
\hline $0-1$ & 215 & 19 & 0.9116 & 0.0884 & 11.8 & 8.3 \\
\hline $1-2$ & 196 & 4 & 0.9795 & 0.0205 & 10.9 & 1.8 \\
\hline $2-3$ & 192 & 3 & 0.9844 & 0.0156 & 10.0 & 1.3 \\
\hline $3-4$ & 189 & 5 & 0.9735 & 0.0265 & 9.1 & 2.2 \\
\hline $4-5$ & 184 & 3 & 0.9837 & 0.0163 & 8.3 & 1.3 \\
\hline $5-6$ & 181 & 6 & 0.9669 & 0.0331 & 7.4 & 2.6 \\
\hline $6-7$ & 175 & 5 & 0.9714 & 0.0286 & 6.6 & 2.2 \\
\hline $7-8$ & 170 & 2 & 0.9882 & 0.0118 & 5.8 & 0.9 \\
\hline $8-9$ & 168 & 0 & - & - & 5.1 & - \\
\hline $9-10$ & 168 & 1 & 0.9940 & 0.0060 & 4.3 & 0.4 \\
\hline $10-11$ & 167 & 2 & 0.9880 & 0.0120 & 3.5 & 0.9 \\
\hline $11-12$ & 165 & 1 & 0.9939 & 0.0061 & 2.7 & 0.4 \\
\hline $12-13$ & 164 & 1 & 0.9939 & 0.0061 & 2.0 & 0.4 \\
\hline $13-14$ & 163 & 2 & 0.9877 & 0.0123 & 1.2 & 0.9 \\
\hline $14-15$ & 161 & 1 & 0.9938 & 0.0062 & - & 0.4 \\
\hline
\end{tabular}

* Twelve removed endoprostheses were eliminated because of unknown in situ times. 
(46 cases, 7.2 percent), trauma ( 38 cases, 5.9 percent) and rheumatoid arthritis (33 cases, 5.2 percent). Ankylosing spondylitis ( 7 cases, 1.1 percent), dislocation ( 7 cases, 1.1 percent), pain without recognizable etiology (6 cases, 0.9 percent) and Paget's disease ( 2 cases, 0.3 percent) were other recorded reasons for total hip prostheses insertion.

Revision of the femoral component with or without acetabular removal was required in 148 of the 641 inserted total hip arthroplasties ( 23.0 percent). Revisions included 126 first revisions, 19 second revisions and 3 third revisions. Removal reasons included loosening or instability (72 cases, 11.2 percent), infection ( 28 cases, 4.4 percent) and pain without known cause ( 21 cases, 3.2 percent). Dislocation ( 6 cases, 0.9 percent) and trauma ( 4 cases, 0.8 percent) were other removal reasons. Three $(0.5$ percent) total hip femoral components were revised due to fracture of the implant stem and one $(0.01$ percent) hip was removed due to acetabular protrusio. The remaining 13 causes for removal were unknown. The insertion and removal data for total hip arthroplasties are presented in Table 3.

A survivorship table (Table 4) was constructed for total hip arthroplasties to determine the expected success of an implant for each year postoperative.

\section{RESULTS}

\section{Endoprosthetic Devices}

Sixty-seven devices (29.5 percent) of the 227 endoprostheses studied, required removal due to patient discomfort. Table 5 summarizes removal data for the endoprostheses. Implant removal was undertaken more frequently in females ( 33.0 percent) than in males ( 22.6 percent). The average weight for male patients at the time of implant insertion was 172.7 pounds, with those requiring revision being slightly heavier, 184.4 pounds. For females, the average weight at insertion was 130.9 pounds, with the patients requiring removal averaging 134.0 pounds.

The average age for patients requiring an endoprosthesis was 66.5 years (range: $21-97$ years), with 77.2 percent of these patients being over 50 years old. The 67 revisions were in patients with an average age at insertion of 55.4 years (range: $21-88$ years), with 64.3 percent of these patients over 50 years old. With respect to age, the failure rate was 43.5
Table 3

Summary of insertion and removal data for total hip prostheses

\section{Insertions}

\begin{tabular}{lcc}
\hline Diagnosis at Insertion & $\begin{array}{c}\text { No. Implants } \\
\text { Inserted }\end{array}$ & $\begin{array}{c}\text { \% of Total } \\
\text { Insertions }\end{array}$ \\
\hline Osteoarthritis & 219 & 34.2 \\
Revision of Previous & 158 & 24.6 \\
Hardware & $(43)$ & $(6.7)$ \\
$\quad$ Total Hips (Both & & \\
$\quad$ Components) & $(31)$ & $(4.8)$ \\
Total Hips (Femoral & & \\
$\quad$ Comp. Only) & $(33)$ & $(5.1)$ \\
$\quad$ Endoprostheses & $(14)$ & $(2.2)$ \\
Surface Replace- & & \\
$\quad$ ments & $(4)$ & $(0.6)$ \\
Bipolar Endo- & & \\
$\quad$ prostheses & $(33)$ & $(5.2)$ \\
$\quad$ Unknown & 66 & 10.3 \\
Aseptic Necrosis & 46 & 7.2 \\
Avascular Necrosis & 38 & 5.9 \\
Trauma & 33 & 5.2 \\
Rheumatoid Arthritis & 7 & 1.1 \\
Ankylosing Spondylitis & 7 & 1.1 \\
Dislocation & 6 & 0.9 \\
Pain & 2 & 0.3 \\
Paget's Disease & 59 & 9.2 \\
Unknown & 641 & 100.0 \\
\hline & &
\end{tabular}

Removals

\begin{tabular}{lcc}
\hline Reason for Removal & $\begin{array}{c}\text { No. Failed } \\
\text { Implants }\end{array}$ & $\begin{array}{c}\text { \% of Total } \\
\text { Insertions }\end{array}$ \\
\hline Loosening/Instability & 72 & 11.2 \\
Infection & 28 & 4.4 \\
Pain & 21 & 3.2 \\
Dislocation & 6 & 0.9 \\
Trauma & 4 & 0.8 \\
Breakage & 3 & 0.5 \\
Shortening & 1 & 0.01 \\
Unknown & 13 & 2.0 \\
\hline
\end{tabular}

percent among those patients who were younger than 50 years of age at insertion and 23.1 percent among those patients who were older than 50 years of age at insertion.

The average time in situ for those endoprotheses requiring revision was 73.7 months (range: 1-180 months). Those patients under 50 years of age at insertion, who required revision, had an average implant in situ time of 78.7 months (range 1-180 months), while those patients over 50 years old at insertion who later required revision had an average implant time in situ of 33.9 months. (range: 1-158 months). 
The highest failure rate for endoprosthetic replacement was among those patients with an insertion diagnosis of osteoarthritis (83.3 percent) after an average time in situ of 76.2 months. Revision of previous hardware produced a 31.6 percent rate of failure after an average of 66.7 months. Nonunion and avascular necrosis accounted for failure rates of 28.6 percent and 21.4 percent, respectively, after an average period of 41.0 months in situ for both. Trauma, the most common insertion diagnosis, was the most successful in enduring endoprosthetic replacement. The failure rate was 16.3 percent, occurring after the shortest average in situ time, 34.4 months.

Endoprostheses removed for pain of unknown cause remained in situ for an average of 77.8 months, while those removed for loosening or instability averaged 48.7 months in situ. Removal for infection occurred after an average of 27.8 months; trauma, 26.5 months; acetabular protrusio, 24.0 months, and dislocation, 2.5 months.

\section{Total Hip Arthroplasties}

Implant removal was required in 23.0 percent (148 cases) of the 641 total hip systems after an average time in situ of 62.1 months. Males and females were equally represented within the failure group, with an approximate 23.0 percent failure rate each. The average patient age at implant insertion for all total hip patients was 55.5 years (range: $18-89$ years), with those patients who required removal averaging
49.9 years at implant insertion. The largest number of patients ( 31.3 percent) were between 50 and 59 years of age at the time of implant insertion. Males tended to be slightly younger, with 35.8 percent below 50 years of age at the time of insertion, as compared to females with 21.2 percent below the age of 50 years. Those patients under 50 years of age had a 34.7 failure rate as opposed to an 18.7 percent failure rate for those patients with insertions after the age of 50. The average time in situ for those patients below the age of 50 at implant insertion which later required implant removal was 62.7 months, as compared to 61.6 months in situ for those patients over 50 .

Table 6 summarizes the removal data for total hip arthroplasties. The total hip implants inserted for trauma had a 44.7 percent failure rate after an average time of 67.5 months. Those implants inserted for aseptic necrosis had a 33.3 percent failure rate after 60.0 months in situ and those inserted for pain of unknown etiology had a 33.3 percent failure rate after 19.0 months in situ. Devices inserted for a diagnosis of avascular necrosis had a 15.2 percent failure rate at an average of 102.7 months in situ. The average time in situ for total hips removed due to breakage was 131.3 months; trauma, 82.5 months; instability, 67.0 months and pain, 58.5 months. Late infections occurred after an average of 42.0 months and dislocations occurred at an average of 21.8 months.

\section{Table 4}

Survivorship table for total hip insertions

\begin{tabular}{|c|c|c|c|c|c|c|}
\hline $\begin{array}{l}\text { Years Post- } \\
\text { Operative }\end{array}$ & $\begin{array}{l}\text { No. of hips } \\
\text { in situ* }\end{array}$ & $\begin{array}{l}\text { No. of } \\
\text { Failures }\end{array}$ & $\begin{array}{l}\text { Probability } \\
\text { of survival }\end{array}$ & $\begin{array}{c}\text { Probability } \\
\text { of failure }\end{array}$ & $\begin{array}{l}\text { Expectation } \\
\text { of life }\end{array}$ & $\begin{array}{l}\% \text { Failure } \\
\text { of Total }\end{array}$ \\
\hline $0-1$ & 617 & 17 & 0.9724 & 0.0276 & 12.6 & 2.7 \\
\hline $1-2$ & 600 & 13 & 0.9783 & 0.0217 & 11.6 & 2.0 \\
\hline $2-3$ & 587 & 12 & 0.9804 & 0.0196 & 10.6 & 1.9 \\
\hline $3-4$ & 575 & 15 & 0.9739 & 0.0261 & 9.7 & 2.3 \\
\hline $4-5$ & 556 & 7 & 0.9875 & 0.0125 & 8.8 & 1.1 \\
\hline $5-6$ & 553 & 13 & 0.9765 & 0.0235 & 7.9 & 2.0 \\
\hline $6-7$ & 540 & 10 & 0.9815 & 0.0185 & 7.0 & 1.6 \\
\hline $7-8$ & 530 & 10 & 0.9811 & 0.0189 & 6.2 & 1.6 \\
\hline $8-9$ & 520 & 9 & 0.9827 & 0.0173 & 5.3 & 1.4 \\
\hline $9-10$ & 511 & 5 & 0.9902 & 0.0098 & 4.5 & 0.8 \\
\hline $10-11$ & 506 & 5 & 0.9901 & 0.0099 & 3.7 & 0.8 \\
\hline $11-12$ & 501 & 3 & 0.9940 & 0.0060 & 2.9 & 0.5 \\
\hline $12-13$ & 498 & 0 & - & - & 2.1 & - \\
\hline $13-14$ & 498 & 1 & 0.9980 & 0.0020 & 1.3 & 0.2 \\
\hline $14-15$ & 495 & 2 & 0.9962 & 0.0038 & - & 0.3 \\
\hline
\end{tabular}

* 24 removed total hip components were eliminated because of unknown in situ times. 
Journal of Rehabilitation Research and Development Vol. 24 No. 3 Summer 1987

Table 5

Removal data for endoprosthetic insertions requiring removal

Insertions

\begin{tabular}{lccc}
\hline Diagnosis at Insertion & $\begin{array}{c}\text { \% Failure } \\
\text { within Group }\end{array}$ & $\begin{array}{c}\text { Average Time } \\
\text { In Situ (mos.) }\end{array}$ & $\begin{array}{c}\text { Ave. Age at } \\
\text { Insertion (yrs.) }\end{array}$ \\
\hline Trauma & 16.3 & 34.4 & 68.5 \\
Revision of Previous Hardware: & 31.6 & 66.7 & 61.8 \\
$\quad$ Endoprostheses & $(10.0)$ & $(168.0)$ & $(40.0)$ \\
$\quad$ Surface Replacements & $(66.7)$ & $(64.0)$ & $(64.0)$ \\
$\quad$ Richards Screw & $(50.0)$ & $(1.0)$ & $(84.0)$ \\
Osteoarthritis & 83.3 & 76.2 & 54.2 \\
Nonunion & 28.6 & 41.0 & 65.3 \\
Aseptic Necrosis & 80.0 & 88.5 & 46.8 \\
Avascular Necrosis & 21.4 & 41.0 & 46.2
\end{tabular}

\section{Removals}

\begin{tabular}{lcc}
\hline Reason for Removal & $\begin{array}{c}\text { Average Time } \\
\text { In Situ (mos.) }\end{array}$ & $\begin{array}{c}\text { Average Age } \\
\text { at Insertion (yrs.) }\end{array}$ \\
\hline Pain & 77.8 & 51.4 \\
Loosening/Instability & 48.7 & 58.4 \\
Infection & 27.8 & 54.0 \\
Dislocation & 2.5 & 70.6 \\
Trauma & 26.5 & 71.0 \\
Shortening & 132.0 & 57.0 \\
Acetabular Protrusio & 24.0 & 79.0 \\
\hline
\end{tabular}

\section{Table 6}

Removal data for total hip arthroplasties requiring removal

\section{Insertions}

\begin{tabular}{lccc}
\hline Diagnosis at Insertion & $\begin{array}{c}\text { \% Failure } \\
\text { within Group }\end{array}$ & $\begin{array}{c}\text { Average Time } \\
\text { In Situ (mos.) }\end{array}$ & $\begin{array}{c}\text { Avg. Age at } \\
\text { Insertion (yrs.) }\end{array}$ \\
\hline Osteoarthritis & 15.1 & 63.1 & 60.7 \\
Revision of Previous Hardware & 14.6 & 37.0 & 55.5 \\
$\quad$ Total Hips (Both Compo- & $(21.9)$ & $(26.1)$ & $(53.7)$ \\
$\quad$ nents) & $(12.9)$ & $(29.5)$ & $(49.5)$ \\
$\quad$ Total Hips (Femoral Comp. & $(6.1)$ & & $(55.5)$ \\
$\quad$ Endoprostheses & 33.3 & 60.0 & $49.6)$ \\
Aseptic Necrosis & 15.2 & 102.7 & 49.4 \\
Avascular Necrosis & 44.7 & 67.5 & 58.4 \\
Trauma & 15.2 & 49.4 & 63.0 \\
Rheumatoid Arthritis & 33.3 & 19.0 & \\
Pain & & & \\
Removals & & & \\
\hline & Average Time & Average Age & \\
Reason for Removal & Situ (mos.) & at Insertion (yrs.) & \\
\hline Loosening/Instability & 67.0 & 53.7 & \\
Infection & 42.0 & 51.9 & \\
Pain & 58.5 & 46.3 & \\
Dislocation & 21.8 & 48.2 & \\
Trauma & 82.5 & 53.7 & \\
Breakage & 131.3 & & \\
\hline
\end{tabular}




\section{DISCUSSION}

The optimum results for endoprosthetic replacement were achieved in the cases of trauma, with a 16.3 percent rate of failure after an average of 34.4 months in situ. Salvati and Wilson (14) using a hip rating system which assigned point values to pain, walking, motion, muscle power, and function, reported that the clinical results for trauma patients were good to excellent after prosthetic replacement in approximately 60 percent of the cases studied. This can be explained in part by the fact that the initial bone stock as well as acetabular articular cartilage is usually in better condition for device implantation following trauma, than when the device is inserted for other disease etiologies.

The highest failure rate ( 83.3 percent) for endoprosthetic replacement was with the insertion diagnosis of osteoarthritis which is also consistent with Salvati and Wilson's (14) findings. Aseptic necrosis had an 80.0 percent failure rate among endoprostheses insertions. In contrast, total hip replacement was much more successful in patients with the initial diagnoses of osteoarthritis and aseptic necrosis, with failure rates of 15.1 percent and 33.3 percent, respectively. It appears that total hip replacement would be the preferred method of treatment for those diagnoses where the acetabulum may become involved. Interestingly, total hip replacement due to trauma had the highest failure rate among total hip insertions ( 44.7 percent) after an in situ time of only 67.5 months. It appears that the insertion of an acetabular component in this instance tends to provide an additional component for potential failure.

The overall failure rate of 23.0 percent for total hip arthroplasties found in this study is higher than that reported in the literature $(10,12,15)$. Within the first postoperative year, 2.7 percent of all inserted total hip devices failed in this study, whereas Morscher (10) found a 0.7 percent incidence of failure within a 1-year period following surgery of Charnley-Muller design total hip prostheses. For comparison, a 14.7 percent failure rate was determined from the survivorship table (Table 4) for the 2-year to 10-year postoperative implantation period. This rate of failure is slightly higher than the 10.4 percent failure rate during the same period reported by Tapadiya (15) for several different implant types. The authors eliminated the first year postoperative failures from the long-term followup results because it was felt that these failures were due directly to the trauma of the surgery and not from the implantation of the hip component.

For the 15-year postoperative period, the rate of failure for endoprostheses was 29.5 percent. Salvati and Wilson (14) found a 10.6 percent rate of failure within the first five years postoperative. From the survivorship table (Table 2), a 14.9 percent failure rate was found for this same period. Endoprosthetic insertions had a higher rate of failure ( 8.3 percent) in the first year compared to that for the total hip arthroplasties, but a slightly lower failure rate (12.7 percent) in the 2-year to 10-year range. The large number of the current cases performed by residents as part of a teaching program could account for the slightly increased number of failures.

The most frequent indication for revision of total hip prostheses during the first postoperative year was infection ( 8 cases, 47.1 percent of first year failures). Andrews (1) reported that the rate of arthroplasty revision due to infection peaks during the first 2 years postsurgery and then declines. The majority of infections ( 72.2 percent) observed in this study occurred within the first 4 years of implantation. However, over the 15-year span of the study, infection resulted in revision in only a small number of cases ( 4.4 percent).

The failure rate for total hip arthroplasties revised due to loosening was 11.2 percent, which is also higher than that reported in the literature $(2,11,15)$. Rates of implant revision reported due to aseptic loosening range from none to 7 percent, with only a few studies reporting higher incidences. Radiographically defined loosening has been reported by Beckenbaugh (2) in 24 percent of reviewed cases, but only 1.7 percent of these cases required revision. The number of cases of loosening did not appear to increase with time as has been reported by Huiskes and others $(6,15)$. Huiskes (6) also strongly suggests that joint replacement be restricted to patients over 60 years of age in order to avoid this complication. The current study supports this age limit. Approximately 74 percent of those components removed for loosening were from patients who were under 60 years of age at the time of implant insertion.

Both endoprosthetic replacements and total hip prostheses had their higher rates of failure in the group of patients under 50 years of age at insertion. For endoprostheses the rate of failure was 43.5 
percent in patients under 50 years versus 23.1 percent in patients 50 years or older. Total hip arthroplasties exhibited a 34.7 percent rate of failure in patients under 50 years versus an 18.7 percent rate of failure in patients over 50 . The average time in situ of total hip insertions for the two age groups was almost identical at approximately 62 months. However, patients under 50 years of age at insertion receiving endoprostheses had a longer average in situ time ( 78.7 months) than that of patients over 50 years (33.9 months). Although no correlation between the insertion diagnoses and the removal reasons could be drawn, 30.4 percent of the failed total hips inserted in patients with previously failed hardware required revision for the same reason.

\section{SUMMARY}

The results of this study reveal that the most significant factors in predicting the potential success in total and endoprosthetic replacement for disorders of the hip joint were patient's age at insertion and the initial insertion diagnosis. The failure rate for both endoprosthetic and total hip replacements was approximately twice as high in patients younger than 50 years of age at the time of insertion when compared to the failure rate for those patients older than 50 years. Age also appeared to be a factor in the expected in situ time for endoprosthetic replacement, with those patients under the age of 50 years at insertion of an endoprosthesis having a mean in situ time almost twice that of the older patients. Total hip arthroplasty appears to be the preferred treatment for metabolic bone diseases, while endoprosthetic replacement appears to be the optimum treatment for disorders affecting only the femoral side of the hip, such as traumatic fracture.

Total hip arthroplasty and endoprosthetic replacement have proven to be successful in relieving hip pain and dysfunction in a large percentage of the cases studied. Within the 15-year time frame, the overall success rates for total arthroplasties and endoprosthetic replacements were 77.0 percent and 70.5 percent, respectively. In determining the best method of treatment based upon long-term successful performance, it is necessary to evaluate individual patient parameters.

\section{REFERENCES}

1. Andrews HJ, Arden GP, Hart GM, Owen JW: Deep infection after total hip replacement. J Bone Joint Surg 63B:53, 1981 .

2. BECKENBAUGH RD AND INSTRUP DM: Total hip arthroplasty: A review of 333 cases with long followup. J Bone Joint Surg 60A:306, 1978.

3. Cotterill P, Hunter GA TILE M: A radiographic analysis of 166 Charnley-Muller total hip arthroplasties. Clin Orthop Rel Res 163:120, 1982.

4. Coventry MB, Beckenbaugh RD, Nolan DR Instrup DM: 2012 total hip arthroplasties: A study of postoperative course and early complications. J Bone Joint Surg 56A:273, 1974.

5. HILL AB: Principles of Medical Statistics. New York: Oxford University Press, 220-236, 1971.

6. HuISKES R: Some fundamental aspects of human joint replacement. Acta Orthop Scand 185(Suppl.):30, 1980.

7. KAY NR: Some complications of total hip replacement. Clin Orthop Rel Res 95:73, 1973.

8. KwOK DC AND CRuess RL: A retrospective study of Moore and Thompson hemiarthroplasty: A review of 599 surgical cases and an analysis of technical complications. Clin Orthop Rel Res 169:179, 1982.

9. MCBETH AA AND Foltz RN: Femoral component loosening after total hip arthroplasty. Clin Orthop Rel Res 141:66, 1979.

10. Morscher E AND Schmassmann A: Failures of total hip arthroplasty and probable incidence of revision surgery in the future. Arch Orthop Traum Surg 101:137, 1983.

11. Nolan DR, Fitzgerald RH, Beckenbaugh RD CovENTRY MB: Complications of total hip arthroplasty treated by reoperation. J Bone Joint Surg 57 A:977, 1975.

12. RITTER MA AND MENDING JB: A comparison of osteonecrosis and osteoarthritis patients following total hip arthroplasty: A long-term followup. Clin Orthop Rel Res 206:139, 1986.

13. Ritter MA, Stringer EA, Littrell DA Williams JG: Correlation of prosthetic femoral head size and/or design with longevity of total hip arthroplasty. Clin Orthop Rel Res 176:252, 1983.

14. Salvat EA AND WILSON PD: Long-term results of femoral head replacement. J Bone Joint Surg 55A:516, 1973.

15. Tapadiya D, Walker RH Schurman DJ: Prediction of outcome of total hip arthroplasty based on initial post-operative radiographic analysis. Clin Orthop Rel Res 186:5, 1984.

16. WILCOCK GK: A comparison of total hip replacements in patients aged 69 or less and 70 years or older. Gerontology 27:1981, 1981. 